\title{
FK960 binding proteins, quinone oxidoreductase 2 and pyridoxal kinase were identified by LC-MS/MS for drug discovery of Alzheimer's treatment
}

\author{
Zenzaburo Tozuka ${ }^{1,2,3 *}$,Akihiro Kunisawa ${ }^{2}$, Fumiyuki Shirai ${ }^{3,4}$ and Yoshinori Ishii ${ }^{3,4}$ \\ ${ }^{1}$ Graduate School of Pharmaceutical Science, Osaka University, Osaka, Japan \\ ${ }^{2}$ Osaka University Shimadzu Analytical Innovation Research Laboratory, Japan \\ ${ }^{3}$ Fujisawa Pharmaceutical Co., Ltd., Osaka, Japan \\ ${ }^{4}$ Astellas Pharma Inc., Tokyo, Japan
}

\begin{abstract}
We established new LC-MS/MS methodology of the target proteome of unknown proteins in cytoplasm of hippocampus for Drug Discovery of Alzheimer's Treatment. Quinone oxidoreductase2 (QR2) of the $25 \mathrm{kDa}$ protein and Pyridoxal kinase (PK) of the $37 \mathrm{kDa}$ protein are the target proteins of Alzheimer's Disease. FK960 binding to QR2 and PK inhibits respectively over-expression of QR2 disturbing memory formation at the cortex and over-phosphorylation of the microtubuleassociated Tau protein accumulated at neurofibrillary tangles in the brains of Alzheimer's disease patients.
\end{abstract}

\section{Introduction}

FK960, [N-(4-acetyl-1-piperazinyl)-p-fluorobenzamide monohydrate], a novel antidementia piperazine derivative, has been shown to reverse scopolamine-induced cognitive deficits in rats in vivo [1], to increase the magnitude of long-term potentiation in guinea pig hippocampus in vitro [2], and improve visual recognition memory in primates [3]. FK960 (100 nM) significantly increased the amplitude of the Excitatory postsynaptic potentials [4]. These studies implicated somatostatinergic, cholinergic, and serotonergic systems. We did not know what kinds of proteins FK960 bind to and act pharmacological effect. For new drug discovery, it is important how to search a small molecule such as FK960 or the small molecule ligands of nuclear receptor (NR) binding promoter DNAs to control transcription of pharmaceutical active proteins such as NF-AT, NF-kB, HDAC, IL-1, TNF and peroxisome [5].

We established new LC-MS/MS methodology of the target proteome of unknown proteins in cytoplasm of hippocampus for Drug Discovery of Alzheimer's Treatment. Quinone oxidoreductase2 (NAD $(\mathrm{P}) \mathrm{H}$ menadione oxido reductase) of the $25 \mathrm{kDa}$ protein and Pyridoxal kinase of the $37 \mathrm{kDa}$ protein are the target proteins of Alzheimer's Disease.

\section{Method}

\section{Synthesis of FK960-immobilized Sepharose 4B}

FK960-immobilized Sepharose 4B was synthesized as shown in Figure 1.

Isolation of FK960 binding proteins in cytoplasm of hippocampus

FK960 binding proteins in cytoplasm of hippocampus was collected from 20 mail Sprague Dawley rats fasted using FK960-immobilized Sepharose 4B incubating with or without FK960 in buffer (50mM

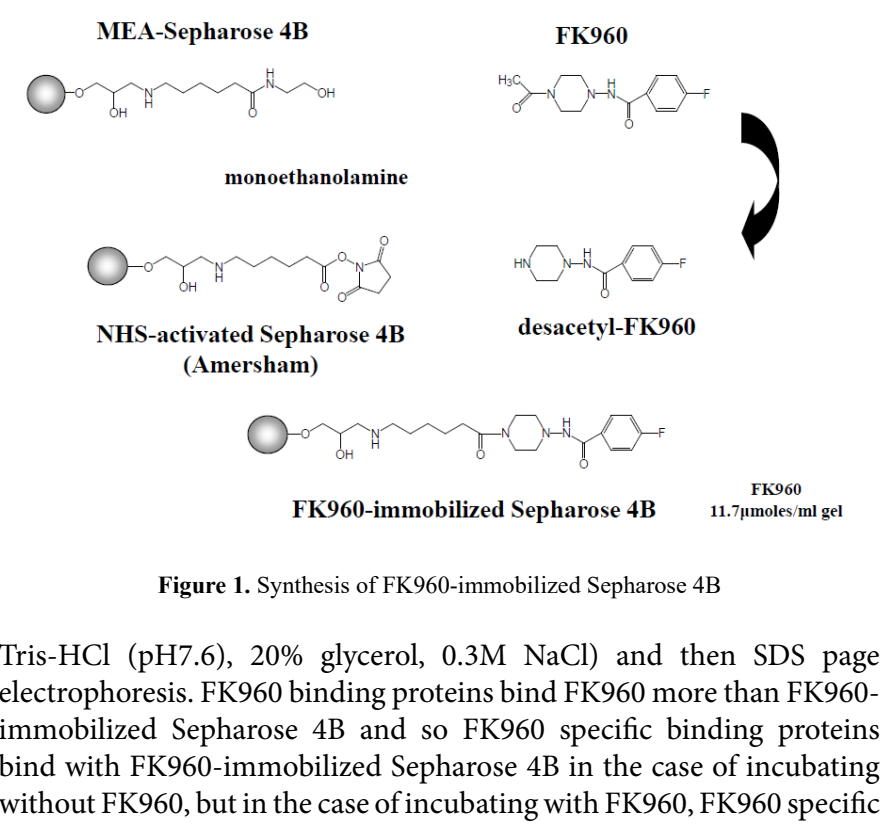

${ }^{*}$ Correspondence to: Zenzaburo Tozuka, Graduate School of Pharmaceutical Science, Osaka University, Osaka; Osaka University Shimadzu Analytical Innovation Research Laboratory; Fujisawa Pharmaceutical Co., Ltd., Osaka, Japan, Tel. +81-6-6879-8167, Fax: +81-6-6879-8167, E-mail: tozuka@phs.osaka-u.ac.jp

Key words: Alzheimer's treatment, pyridoxal kinase, quinone oxidoreductase2, FK960, ESI Ion Trap MS

Received: July 28, 2018; Accepted: August 14, 2018; Published: August 16, 2018 
binding proteins do not bind with FK960-immobilized Sepharose 4B as shown the methodology isolating FK960 binding proteins in Figure 2.

\section{LC-MS/MS analysis of FK960 binding proteins after in gel digestion of SDS page spots}

FK960 binding protein bound with FK960-immobilized Sepharose 4B was eluted with FK960 after washing out another protein. The elute, the washout solution and the incubating solution with FK960 were compared the containing proteins using SDS page electrophoresis in both MES buffer and MOPS buffer in Figure 3 and Silver stain (in NuPAGE $4-12 \%$ Bis-Tris Gel MOPS buffer) and CBB stain in Figure 4. In the SDS page, the - marked bands contained $37 \mathrm{kDa}$ protein and $25 \mathrm{kDa}$ protein, but the + marked band did not contain them. $37 \mathrm{kDa}$ protein and $25 \mathrm{kDa}$ protein stained bands were cut off from the gel, and proteins were reduced by dithiothreitol, alkylated by iodoacetamide (SIGMA, St Louis, MO) and digested by Trypsin that had been modified for peptide sequencing (Roche, Mannheim, Germany). We carried out this in-gel digestion according to a previous report. (The total amount of precipitate was dissolved in $4 \mathrm{~mL}$ of $6 \mathrm{~mol} / \mathrm{L}$ guanidine, $0.1 \mathrm{~mol} / \mathrm{L}$ tris and $1 \mathrm{mmol} / \mathrm{L}$ EDTA buffer (pH8.3). After $300 \mu \mathrm{mol} \mathrm{DTT} \mathrm{treatment}$ to reduce S-S bond, $500 \mu \mathrm{mol}$ iodoacetic acid treatment to protect the produced SH group by carboxymethylation and a micro dialysis with a $6 \mathrm{kDa} \mathrm{MW}$ cut-off membrane, trypsin $(2 \% \mathrm{w} / \mathrm{w})$ was added to the solution and incubated at $37^{\circ} \mathrm{C}$ for 4 hours and lyophilized.

LC-MS/MS analysis of $37 \mathrm{kDa}$ protein and $25 \mathrm{kDa}$ protein were conducted after in gel digestion of the spot in SDS-page electrophoresis using nanoLC MAGIC 2002 (Magic C18 column $(0.75 \mathrm{~mm} \times 150 \mathrm{~mm}$, $3.5 \mu \mathrm{m})$, Mobile phase ((A) $0.1 \%(\mathrm{v} / \mathrm{v}) \mathrm{AcOH}$ in Water, (B) $0.1 \%(\mathrm{v} / \mathrm{v})$ $\mathrm{AcOH}$ in acetonitrile, Gradient $(0-5 \mathrm{~min}(\mathrm{~B} ; 5 \%), 5-45 \mathrm{~min}(\mathrm{~B} ; 5-45 \%)$, 45-55min (B;45-90\%), 55-90min (B;90\%),90-91min (B;90-5\%),91$95 \mathrm{~min}(\mathrm{~B} ; 5 \%))$, Flow rate $(50 \mathrm{~nL} / \mathrm{min}))$ and ThermoFinnigan ion trap LCQ Deca MS under MS condition of analysis (Sheath gas (75), Auxiliary gas (15), Capillary temperature $\left(300^{\circ} \mathrm{C}\right)$, Scan mode (LC/ESI/ MS/MS (positive mode, data dependent scan)).

\section{Result}

The high sensitive nanoLC-MS/MS measurement was conducted after in-gel digestion of both spots of $37 \mathrm{kDa}$ protein and $25 \mathrm{kDa}$ protein of SDS page electrophoresis. The following unknown $37 \mathrm{kDa}$ protein and $25 \mathrm{kDa}$ protein were identified by Bioworks Sequest (Thermo Electron) having high protein coverage, many repeat number of appearance, high quality of mass spectrum and high total score, and using rat and nr fasta data base. Mass Chromatogram (top), mass spectrum (middle) and MS/MS spectrum of $25 \mathrm{kD}$ a protein in SDS page electrophoresis are

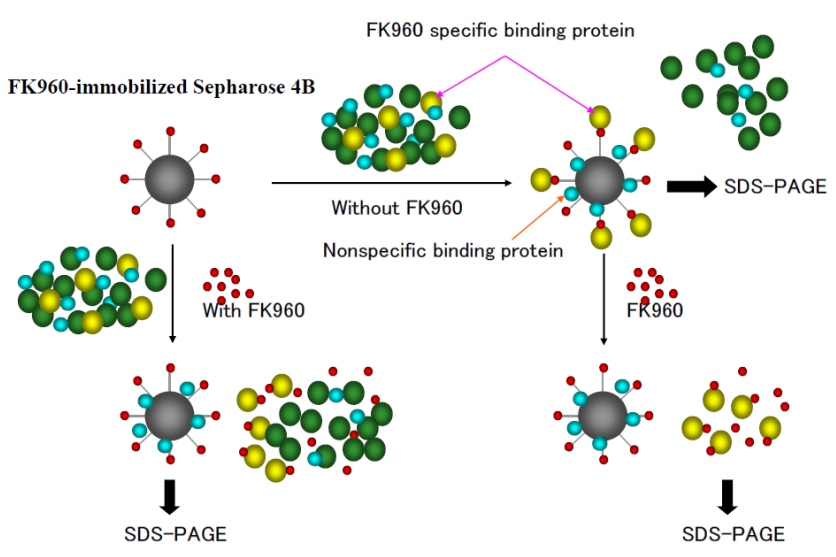

Figure 2. The methodology isolating FK960 binding proteins

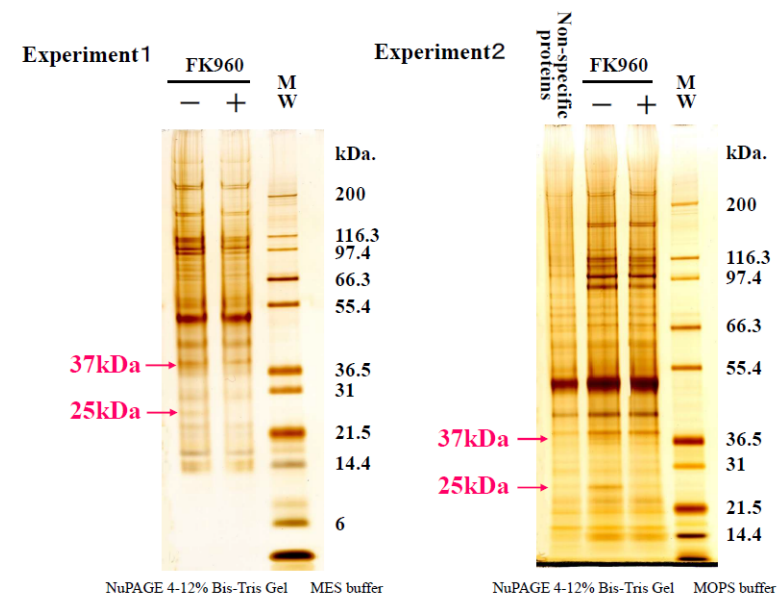

(Expand)
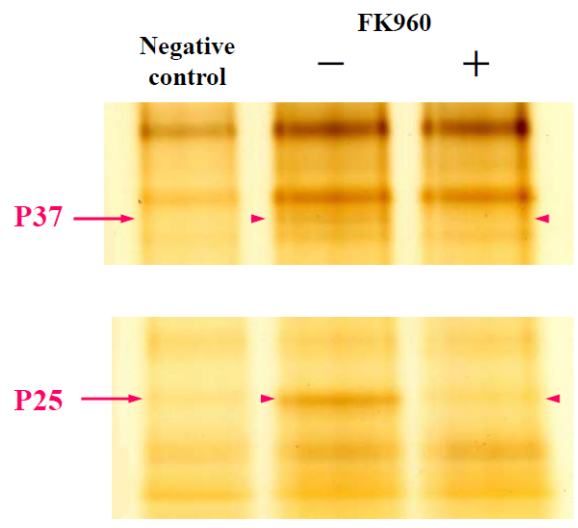

Figure 3. SDS page electrophoresis 1 isolating FK960 binding proteins + and -marks mean incubation with or without FK960

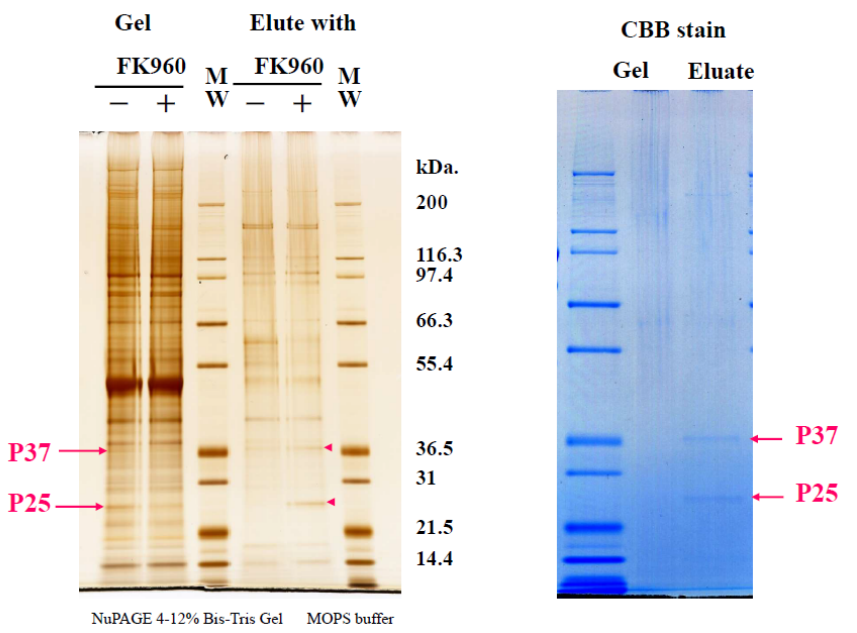

Figure 4. SDS page electrophoresis 2 isolating FK960 binding proteins + and -marks mean incubation with or without FK960

shown in Figure 5. Mass Chromatogram (top), mass spectrum (middle) and $\mathrm{MS} / \mathrm{MS}$ spectrum of $37 \mathrm{kDa}$ protein in SDS page electrophoresis are shown in Figure 6.

The $25 \mathrm{kDa}$ protein was assigned Quinone oxidoreductase2 $(\mathrm{NAD}(\mathrm{P}) \mathrm{H}$ menadione oxidoreductase) that had never identified in rat 


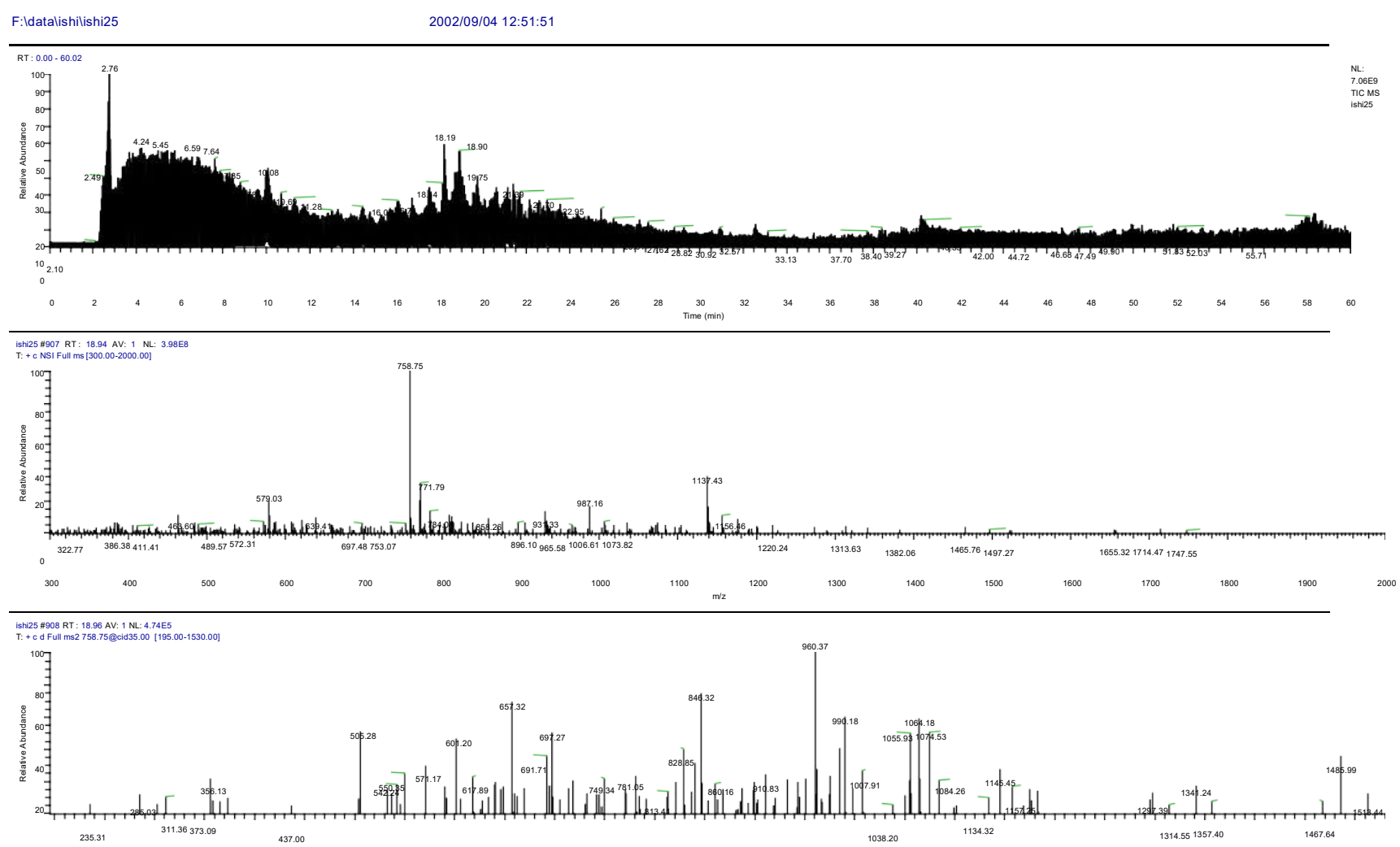

Figure 5. Mass Chromatogram (top), mass spectrum (middle) and MS/MS spectrum (bottom) of 25kDa protein in SDS page electrophoresis

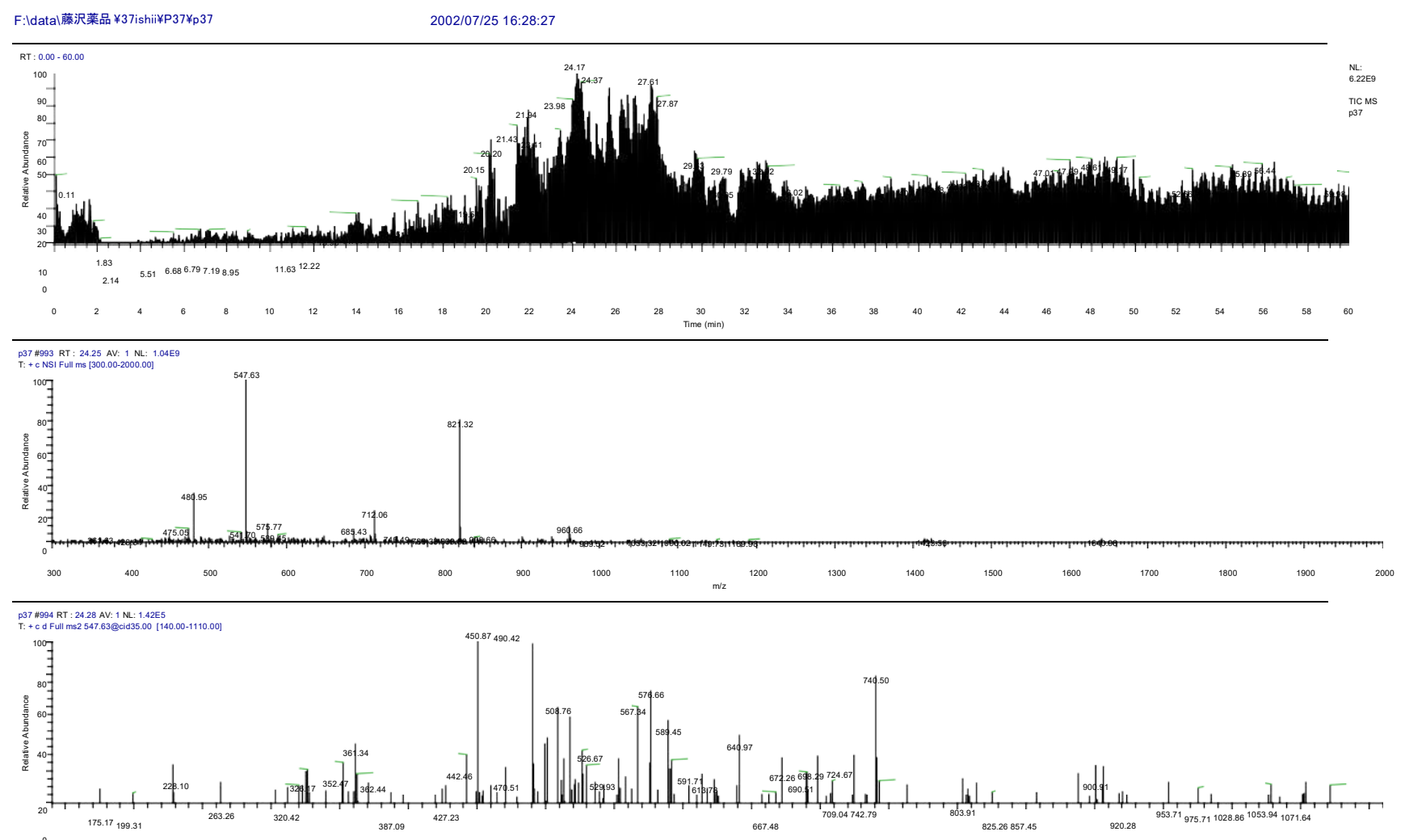

Figure 6. Mass Chromatogram (top), mass spectrum (middle) and MS/MS spectrum (bottom) of 37kDa protein in SDS page electrophoresis 
and so used $n r$ fasta database having protein coverage $52 / 231=22.5 \%$ by amino acid count, many repeat number of appearance, high total score in Figure 7 and high quality of MS/MS spectrum in Figure 8.

The $37 \mathrm{kDa}$ protein was assigned Pyridoxal kinase having monoisotopic mass $=34867$, Protein Coverage: $108 / 312=34.6 \%$ by amino acid count, $11857 / 34867=34.0 \%$ by mass, many repeat number
20

30 of appearance, high total score in Figure 9 and high quality of MS/MS spectrum in Figure 10.

\section{Discussion}

We believe a new mechanism by FK960 binding 25kDa protein assigned Quinone oxido reductase2 (QR2) and FK960 binding 37kDa

MAGKKVLIVY AHQEPKSFNG SLKKVAVEEL SKQGCTVTVS DLYSMNFEPR

ATRNDITGAP SNPDVFSYGI ETHEAYKKKA LTSDIFEEQR KVQEADLVIF

QFPLYWFSVP AILKGWMDRV LCRGFAFDIP GFYDSGFLKG KLALLSLTTG

GTAEMYTKDG VSGDFRYFL PLQHGTLhFC GFKVLAPQIS FGLDVSSEEE

RKVMLASWAQ RLKSIWKEEP IHCTPPWYFQ E

Gene name: mouse Nqo2 GenBank No. NM_020282 (2002), 693bp, 231aa. Molecular weight:

26,231

Figure 7. Quinone oxidoreductase 2 of the $25 \mathrm{kDa}$ protein assigned by Bioworks Sequest soft using nr fasta database
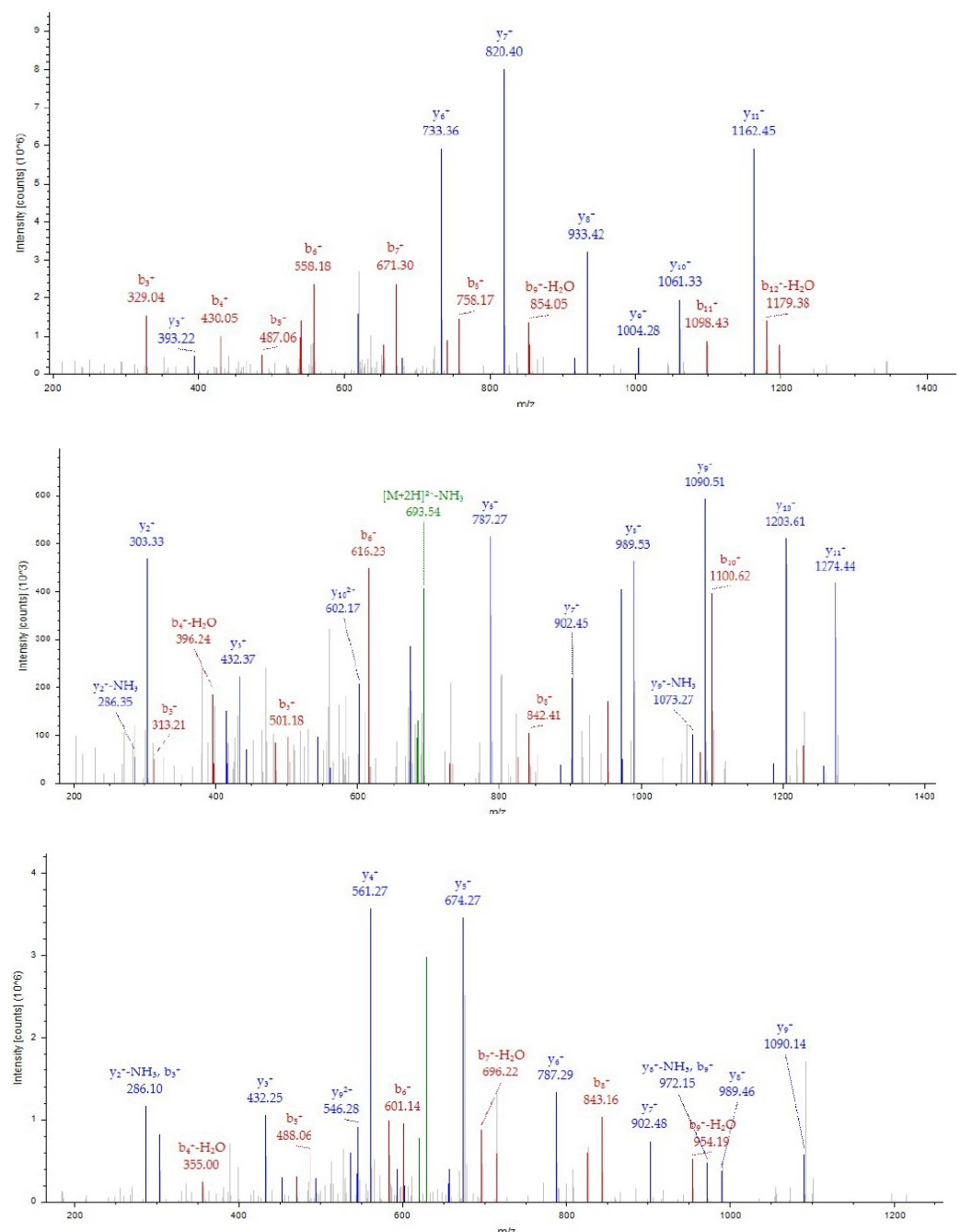

Figure 8. MS/MS spectrum of Quinone oxidoreductase 2 of the $25 \mathrm{kDa}$ protein assigned by Bioworks Sequest soft using nr fasta database 
MEGECRVLSI QSHVVRGYVG NRAAMFPLQV LGFEVDAVNS VQFSNHTGYA

HWKGQVLTSQ ELHALYEGLK ANNVNKYDYV LTGYTRDKSF LGMVVDIVQE

LKOONSRLVY VCDPVMGDKW NGEGSMYVPQ DLLPVYREKV VPMADIITPN

QFEAELLSGR KIHSOEEAFA VMDVLHRMGP DTVVITSSDL PSPKGSDYLM

ALGSQRMRKP DGSTVTQRIR MEMRKVDPV VGTGDLFAAM LLAWTHKHPD

NLKVACEKTV SAMQHVLQRT IRCAKAEAGE GQKPSPAQLE LRMVQSRKDI

Gene name: rat Pdxk

GenBank No. AF020346 (1997)

936bp, 312aa.

Molecular weight: $\mathbf{3 4 , 8 8 5}$

EDPEIVVQAT VI

Figure 9. Pyridoxal kinase of the $37 \mathrm{kDa}$ protein assigned by Bioworks Sequest soft using $\mathrm{nr}$ fasta database
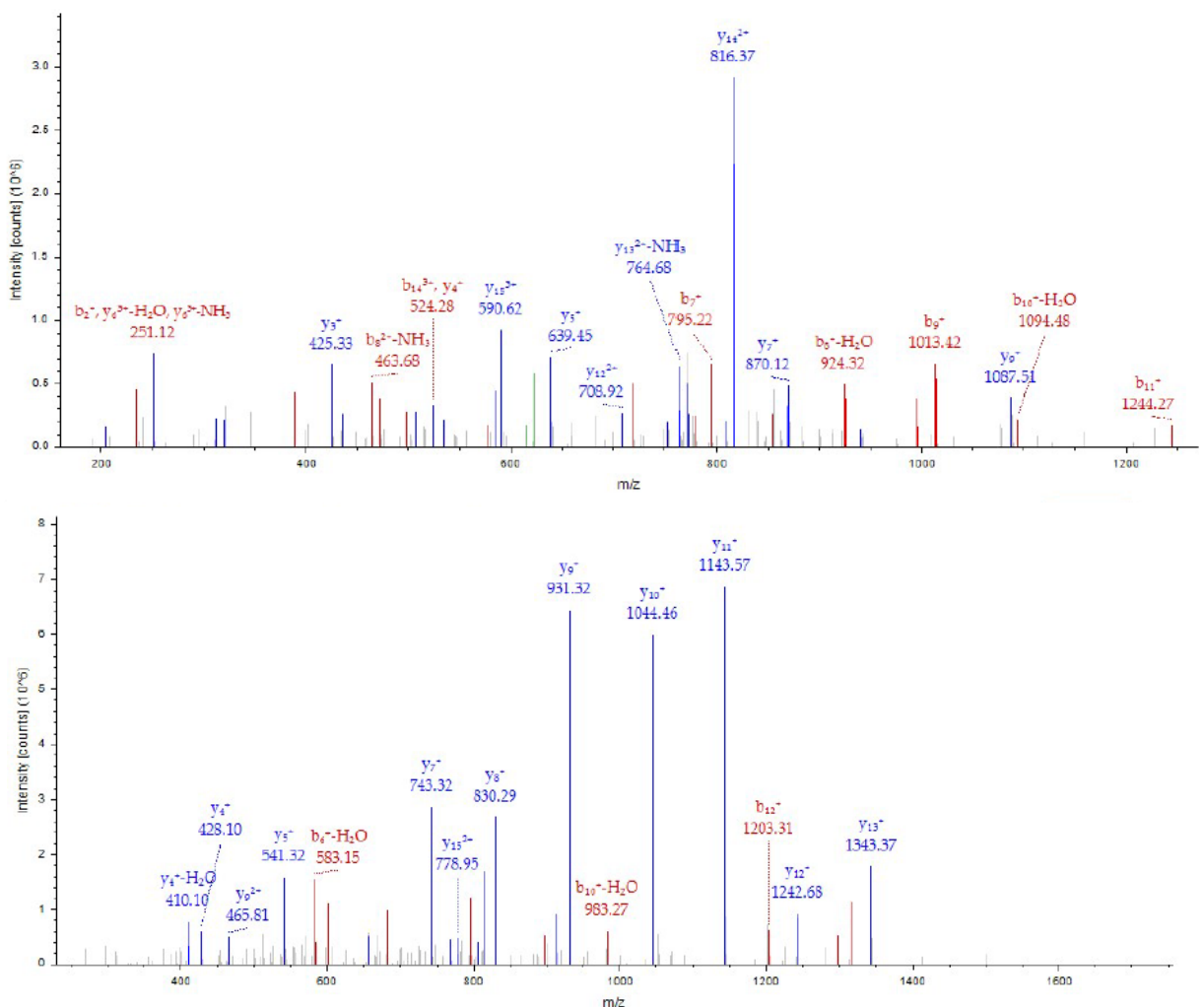

Figure 10. MS/MS spectrum of Pyridoxal kinase of the 37kDa protein assigned by Bioworks Sequest soft using nr fasta database

protein assigned Pyridoxal kinase (PK) to inhibit respectively overexpression of QR2 disturbing memory formation at the cortex [6] and over-phosphorylation of the microtubule-associated Tau $[7,8]$ protein accumulated at neurofibrillary tangles in the brains of Alzheimer's disease patients as described by many scientists [9-12].

We also believe this methodology is useful to find small molecule ligands of nuclear receptor (NR) binding promoter DNAs to control transcription of pharmaceutical active proteins such as NF-AT, NF-kB, HDAC, IL-1, TNF and peroxisome.

\section{Acknowledgements}

We would express our special thanks to Managing Editor Sandy Williams of Trends in Research, Dr. G.C. Stafford, Prof. D. Hunt, and Prof. R.G. Cooks for Inventors of ThermoFinnigan Ion Trap LCQ Deca MS who teach us MS good hand operation.

\section{Conflicts of interest}

The authors declare no conflict of interest.

\section{References}

1. Matsuoka N, Satoh M (1998) FK960, a novel potential anti-dementia drug, augments long-term potentiation in mossy fiber-CA3 pathway of guinea-pig hippocampal slices. Brain Res 794: 248-254. [Crossref]

2. Matsuoka N, Satoh M (1998) FK960, a novel potential anti-dementia drug, augment long-term potentiation in mossy fiber-CA3 pathway of guinea-pig hippocampal slices. Brain Res 794: 248-254. [Crossref]

3. Matsuoka N and Aigner TG (1997) FK960, N-(4-acetyl-1-piperazinyl)-pfluorobenzamide monohydrate], a novel potential anti-dementia drug, improves visual recognition memory in rhesus monkeys: comparison with physostigmine. J Pharmacol Exp Ther 280: 1201-1209.

4. Hodgkiss JP, Kelly JS (2001) Effect of FK960, a putative cognitive enhancer, on synaptic transmission in CA1 neurons of rat hippocampus. J Pharmacol Exp Ther 297: 620-628. [Crossref] 
5. Tozuka Z, Kunisawa A (2018) Multi Omics by LC-MS/MS to search small molecule ligands of nuclear receptors to control transcription of pharmaceutical active proteins for drug discovery. Trends Res 1: 111

6. Akiva N, Rappaport AN, Jacob E, Sharma X, Inberg S, et al. (2015) Expression of Quinone Reductase-2 in the cortex is a muscarinic acetylcholine receptor-dependent memory consolidation constraint. $J$ Neuroscience 35 : 15568-15581.

7. Aizawa H, Kawasaki H, Murofushi H, Kotani S, Suzuki K, et al. (1989) A common amino acid sequence in $190-\mathrm{kDa}$ microtubule-associated protein and tau for the promotion of microtubule assembly. J Biol Chem 264: 5885-5890. [Crossref]

8. Aizawa H, Kawasaki H, Murofushi H, Kotani S, Suzuki K, et al. (1989) A common amino acid sequence in $190-\mathrm{kDa}$ microtubule-associated protein and tau for the promotion of microtubule assembly. J Biol Chem 264: 5885-5890. [Crossref]
9. Aizawa H, Kawasaki H, Murofushi H, Kotani S, Suzuki K, et al. (1989) A common amino acid sequence in $190-\mathrm{kDa}$ microtubule-associated protein and tau for the promotion of microtubule assembly. J Biol Chem 264: 5885-5890. [Crossref]

10. Kimura T, Ishiguro K, Hisanaga S (2014) Physiological and pathological phosphorylation of tau by Cdk5. Front Mol Neurosci 7: 65. [Crossref]

11. Crowther RA, Goedert M (2000) Abnormal tau-containing filaments in neurodegenerative diseases. J Struct Biol 130: 271-279. [Crossref]

12. Lee VM, Kenyon TK, Trojanowski JQ (2005) Transgenic animal models of tauopathies. Biochim Biophys Acta 1739: 251-259. [Crossref]

13. Otth C, Concha II, Arendt T, Stieler J, Schliebs R, et al. (2002) AbetaPP induces cdk5 dependent tau hyperphosphorylation in transgenic mice Tg2576. J Alzheimers Dis 4 : 417-430. [Crossref]

Copyright: $@ 2018$ Tozuka Z. This is an open-access article distributed under the terms of the Creative Commons Attribution License, which permits unrestricted use, distribution, and reproduction in any medium, provided the original author and source are credited. 